\title{
A CLINICAL AND PATHOLOGICAL STUDY OF FATAL CASES OF STATUS ASTHMATICUS
}

BY

\author{
J. C. HOUSTON, S. DE NAVASQUEZ, AND J. R. TROUNCE \\ From the Departments of Medicine and Pathology, Guy's Hospital, London
}

(RECEIVED FOR PUBLICATION JUNE 22, 1953)

\begin{abstract}
Although over 200 fatal cases of asthma have been reported with detailed microscopic findings (Unger, 1945) the train of events leading to death in status asthmaticus is still not fully understood.

The obscurity is largely due to the inherent difficulty in assessing the relative importance of the pathological changes found, but has been increased by the fact that not all the patients whose cases are on record had died in attacks of uncomplicated asthma. It was therefore decided to study a group of patients, who had died in status asthmaticus but showed no clinical or pathological evidence of respiratory infection or pulmonary heart disease, in an attempt to elucidate the pathogenesis of the condition.
\end{abstract}

\section{Materials AND Methods}

The patients selected for study had all died in Guy's Hospital in attacks of asthma which had not responded to adrenaline or other anti-spasmodics. In no case was there fever, leucocytosis, or pathological change indicating pneumonia or other inflammatory complication, nor was there any evidence of pulmonary heart disease.

Macroscopic findings had been reported in nine necropsies and tissues were available for microscopy in six. Sections were taken from the lung at various levels of the bronchial tree to include major bronchi, bronchioles, and alveoli. These were stained by the usual histological methods including haematoxylin and eosin, Van Gieson's and Weigert's stains for collagen and elastic tissues, periodic-acid-Schiff (P.A.S.) for mucus and mucopolysaccharides, and silver impregnation for reticulin.

\section{CAse Reports}

CASE 1.-This was a woman aged 48. One aunt had died of asthma when aged 30 and her mother had died in status asthmaticus at the age of 48 . The patient had had almost continuous asthma since it started rather suddenly when she was 46 . She needed treatment in hospital on several occasions and was in hospital for the last six months of her life. There were no known precipitating factors for her attacks, but there was a history of long-standing financial and domestic anxiety. A great many treatments were tried including all the usual anti-spasmodics. Cortisone produced a temporary remission in her symptoms, but she relapsed and died suddenly in her sleep. There was an eosinophilia of 1,450 per c.mm. in the peripheral blood.

Necropsy. - The heart was normal (weight 290 g.). The bronchi were filled with mucus. The lungs were emphysematous and dry (right lung, $470 \mathrm{~g}$.; left lung, 360 g.). The pleurae were normal.

CASE 2.-A woman aged 33 had had only mild asthma from the age of 16 until a year before her death when she had to be admitted to hospital in a very severe attack. On her final admission she had been in status asthmaticus for three days. She was collapsed (blood pressure $80 / 20 \mathrm{~mm} . \mathrm{Hg}$ ), and in spite of treatment with adrenaline, oxygen, intravenous fluids, and cortisone she died the next day. In the 24 hours before she died she had received $28 \mathrm{ml}$. paraldehyde intramuscularly.

Necropsy.-The heart was normal $(257$ g.). The bronchi were filled with mucus. The lungs were pale, dry, and emphysematous (right lung, $335 \mathrm{~g}$.; left lung, 375 g.). The pleurae were normal.

CASE 3.-This was a man aged 47. His father had died of asthma at the age of 61 . The patient had had asthma for seven years. It was well controlled with adrenaline and ephedrine until the day before admission to hospital, when he developed a severe attack which persisted in spite of treatment. No particular precipitating cause could be found. He was given cortisone, but made no real progress and died quite suddenly two days after admission.

Necropsy.-The heart was normal $(247$ g.). The bronchi were plugged with clear, thick mucus. The lungs were emphysematous and dry (right lung, $305 \mathrm{~g}$.; left lung, $320 \mathrm{~g}$.). The pleural cavities were normal.

CASE 4.-This was a woman aged 53. Although her asthma started at the age of 7 she had had a very long remission and the disease had been really troublesome for the last three years only. For the last four months it had been almost continuous. Pollen and dust precipitated her attacks. She improved in hospital while under treatment with adrenaline and breathing exercises, but following the suggestion that she should 
return home she developed a severe attack which failed to respond to anti-spasmodics and died suddenly in her sleep. She was given $5 \mathrm{ml}$. paraldehyde intramuscularly five hours before her death.

Necropsy.-The heart was normal. The lungs were emphysematous and the bronchi plugged with mucus (no weights of these organs were recorded).

CASE 5.-A woman aged 53 had had asthma for only nine months and for the last four months it had been almost continuous. Six weeks before her admission she developed a rash similar to erythema nodosum. No precipitating cause for her asthma could be found, though there was a background of domestic worry. She was admitted in status asthmaticus which responded temporarily to anti-spasmodics, but died after a severe attack which had lasted 24 hours. An eosinophilia of 651 per c.mm. was found in the peripheral blood. She was given $7 \mathrm{ml}$. paraldehyde by mouth shortly before her death.

Necropsy.-The heart was normal (270 g.). The bronchi were filled with thick mucus. The lungs were emphysematous and dry (right lung, $480 \mathrm{~g}$.; left lung, 400 g.).

CASE 6.-A woman aged 64 had suffered from hay fever sirce childhood and developed asthma at the age of 42 at the time of a nervous breakdown which followed the death of her first husband. The attacks had been much more severe in the last three years and she had been in hospital in status asthmaticus on one previous occasior. No precipitating cause for her attacks was found. She improved at first under treatment with adrenaline and aminophylline, but after two weeks developed a further severe attack which did not respond to adrenaline. After about 18 hours in this attack she died quite suddenly. An eosinophilia of 896 per c.mm. was found in the peripheral blood.

Necropsy. - The heart was normal (260 g.). The bronchial tree was plugged with mucus. The lungs were pale, dry and emphysematous (weights : right lung, $450 \mathrm{~g}$.; left lung, $350 \mathrm{~g}$.). The pleural cavities were normal.

CASE 7.-This was a woman aged 26. One cousin suffered from asthma. The patient developed asthma while on her honeymoon at the age of 22 . The attacks slowly became more severe and more frequent and she had to be admitted to hospital on five occasions in status asthmaticus. There was some suggestion of domestic discord. A mild but persistent attack of asthma occurred two weeks before her final admission to hospital. This became worse in the last 36 hours and she was given morphine, $\frac{1}{4}$ grain $(15 \mathrm{mg}$.). On admission she was cyanosed and collapsed (blood pressure $80 /$ ? $\mathrm{mm}$. $\mathrm{Hg}$ ). She improved temporarily after being given oxygen and adrenaline, but a few hours later collapsed and died.

Necropsy.-The heart was normal (200 g.). The bronchial tree was filled with mucus. The lungs were pale, dry, and emphysematous (right lung, $285 \mathrm{~g}$.; left lung, 320 g.). The pleurae were normal.

CASE 8.-A woman aged 46 developed asthma after influenza at the age of 43 . Factors producing attacks were aspirin, hay, and dust. The asthma became progressively worse and she was in hospital with a severe continuous attack, which responded poorly to adrenaline, for six weeks before her death. Thirty-six hours before she died she was given morphine, $\frac{1}{4}$ grain (15 mg.), because of her extreme restlessness, and two hours before death she became very noisy and irrational. She died suddenly.

Necropsy.-The heart was normal (215 g.). The lungs were emphysematous and the bronchi filled with thick plugs of mucus (right lung, $585 \mathrm{~g}$.; left lung, $420 \mathrm{~g}$.). The pleurae were normal.

CASE 9.-A woman aged 47 , since the age of 39 , had suffered from asthma, which was usually mild but had necessitated her admission to hospital on two occasions. The attacks appeared to be precipitated mainly by emotional upsets, and skin tests had shown her to be sensitive to mixed house dust. The final attack started one month before her admission to hospital; it had become gradually more severe and less responsive to anti-spasmodics. In hospital there was slight initial improvement, though wheezing persisted, and on the fourth day she collapsed quite suddenly and died within a few minutes. Eosinophilia of 2,375 per c.mm. had been found in the peripheral blood.

Necropsy. - The heart was normal (235 g.). The bronchial tree was filled with clear mucus. The lungs were pale, dry, and emphysematous (right lung, $390 \mathrm{~g}$.; left lung, $380 \mathrm{~g}$.). The pleural membranes were normal.

\section{HistologY}

Sections of the lungs were available in Cases 2, $3,6,7,8$, and 9, and, since the microscopic appearances were similar in all respects, the following description is applicable to all six.

The lumen of all the bronchi and bronchioles examined was almost entirely filled with mucus which stained homogeneously bright red with P.A.S. and contained richly cellular spirals composed of eosinophil polymorph leucocytes and detached ciliated epithelial cells, intimately mixed in varying proportions (Fig. 1). This mucus appeared to be a continuous mass extending from the major bronchi down to the bronchioles and only partially separated at various points from the bronchial wall. The latter showed the most characteristic changes, of which the following were the most conspicuous: (1) Partial or complete detachment of the superficial ciliated epithelium from all the bronchi, leaving only a thin and generally single-celled layer of reserve or basal short non-ciliated cells as a lining which was continuous with the normal and similar lining of the bronchioles (Fig. 2). (2) Bronchial constriction, indicated by crenation of the wall and "diverticulosis" of the epithelium, was present in a majority of the medium-sized bronchi of 2-5 mm. diameter (Fig. 3) though some of the 
smaller bronchi and bronchioles appeared to be distended (Fig. 4). It is difficult to assess the degree of constriction in the absence of such changes as crenation of the remaining epithelium. Changes in the bronchial wall consisted mainly of thickening of the so-salled " basement membrane" which stained red with Van Gieson stain, pink with P.A.S., and black with silver stains and was therefore mainly of a collagenous nature (Fig. 5). Goblet cells were present in the residual epithelium, but it was not possible to decide whether they were increased or not. There were a few areas of squamous metaplasia showing stratification, but these were inconspicuous (Fig. 6). Local eosinophilia was present in varying degrees in all the layers of the bronchial wall. No quantitative or qualitative abnormality could be detected in the mucous glands. (4) Emphysema was widespread and the alveoli mostly contained air and showed marked thinning of the walls. The blood vessels appeared normal and there was no evidence of inflammatory disease.

\section{Discussion}

There is general agreement on the major pathological findings of plugging of the bronchial tree with mucus, eosinophilia, thickening of the basement membrane, and emphysema (Huber and Koessler, 1922; Thieme and Sheldon, 1938; Unger, 1945; Thomson, 1945). The interpretation of these findings and their significance in the pathogenesis of status asthmaticus is still in dispute. Huber and Koessler (1922) attributed them to an " exudative process." Moore (1925) was the first to point out that defective ciliary action is a factor of the utmost importance in producing stagnation of mucus and advocated bronchoscopic drainage. Hilding (1943) also stressed the importance of ciliary activity in maintaining the flow of mucus, and in 12 out of 31 cases of fatal asthma described what he called "metamorphosis of ciliated cell to goblet cell and the appearance of mucus in the ciliated cell in the form of a droplet which lifts the plate of cilia from the cell." We have found no evidence of this change in our own material though an occasional small area of squamous metaplasia has been seen. What has been a constant change, however, is a diffuse detachment of the superficial ciliated epithelium which is seen to be intimately mixed with eosinophils in the centre of the mucus in the bronchial lumen, leaving the wall of the bronchus lined by non-ciliated basal type of epithelium. This shedding of the ciliated epithelium cannot be ascribed to post-mortem artefact as it is not seen in the lungs of patients who have died of other conditions. Moreover, detached ciliated cells can be seen in the Curschmann's spirals which are expectorated during an attack of asthma (Curschmann, 1883). Furthermore, Thomson (1945) described similar detachment of ciliated epithelium in an ovarian teratoma which contained respiratory type of epithelium resting on smooth muscle and which showed the typical " asthmatic reaction" of eosinophilia and thickening of the basement membrane. This case reported by Thomson is of considerable interest because the patient died during an attack of asthma, and necropsy showed all the characteristic changes in the bronchial tree and in addition similar changes in an ovarian teratoma which contained an area of respiratory epithelium. There is no evidence of degenerative changes in such detached epithelium; indeed the cilia are usually well preserved, thereby strongly suggesting a mechanical separation of otherwise normal epithelium. This may be the result of constriction of the bronchial muscle with consequent narrowing of the circumference and diminution of the area to which the epithelium is attached, which would lead to crenation and if sufficiently severe might cause actual shedding of epithelium. The stage of diffuse epithelial detachment is clearly an irreversible one until such time as regeneration of ciliated epithelium can occur. It is not known how long it takes for regeneration to be sufficient to start the flow of mucus.

The thickening of the basement membrane is seen to consist mainly of collagen and appears to merge with the lamina propria and surrounding peribronchial connective tissue; its significance is u. known.

Emphysema is another constant finding. The weight of the heart was, however, below $300 \mathrm{~g}$. in all our cases, so that there was no pathological evidence of chronic pulmonary heart disease.

\section{Clinical Aspects}

The clinical features of our patients are summarized in the Table. They all developed asthma in adult life and in five the age of onset was $\mathbf{4 0}$ or over. This suggested the possibility that asthma developing late in life is particularly liable to end in death from status asthmaticus; Rackemann (1944) reached the same conclusion from analysis of his cases, but was unable to confirm the observation from study of the literature. Bullen (1952), however, from a study of 176 fatal cases of asthma concluded that the prognosis was much worse in those whose asthma began when they were over 40 years of age than in those who first had symptoms before the age of 25 . There were no children 


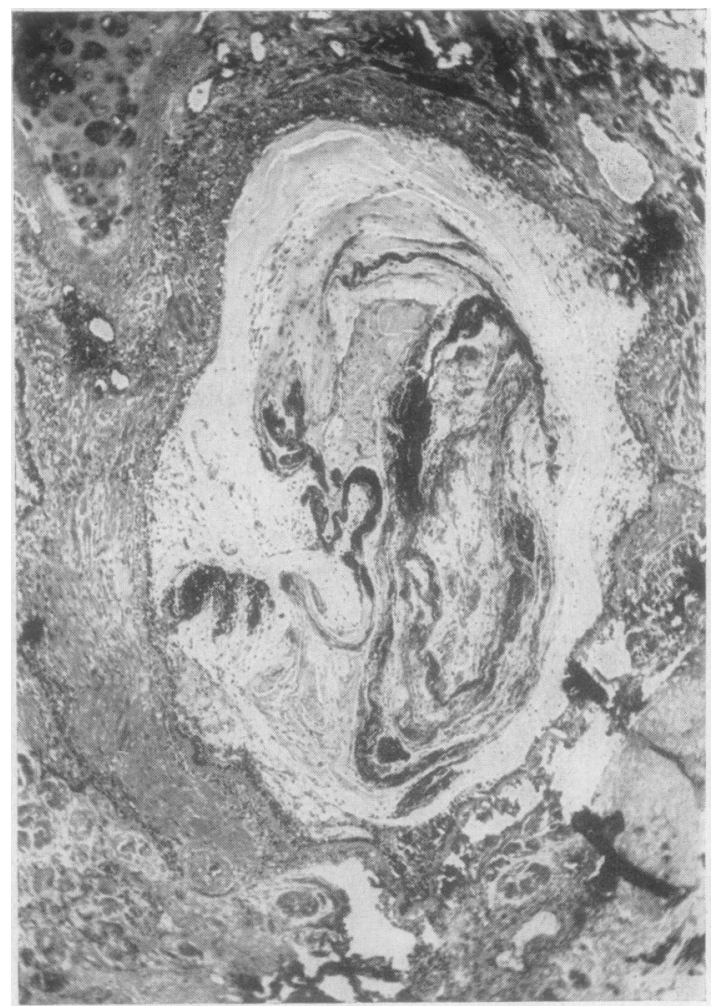

FIG. I

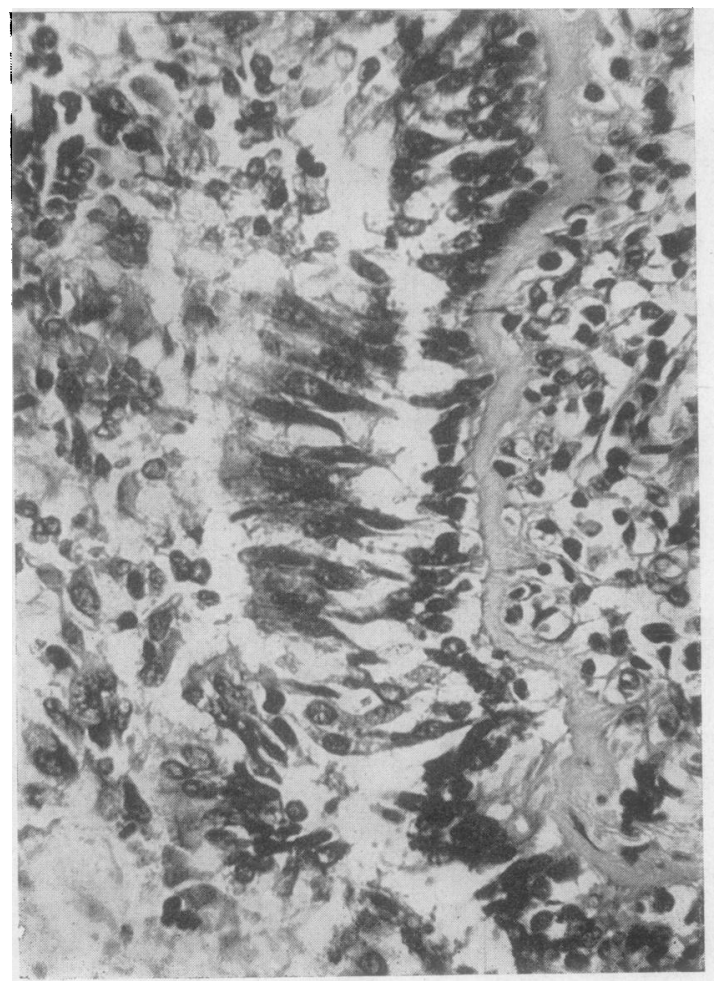

FIG. 2
FIG. 1-Photomicrograph of small bronchus showing mucous plug with central spirals of detached epithelium. Haematoxylin and eosin, $\times 40$.

FIG. 2.-Photomicrograph of bronchial wall showing the ciliated epithelium becoming separated, leaving only the reserve basa cells attached to the basement membrane. Haematoxylin and eosin, $\times 340$.

FIG. 3.-Photomicrograph showing crenation and diverticulosis of bronchial epithelium indicative of constriction. Haematoxylin $C$ and eosin, $\times 100$

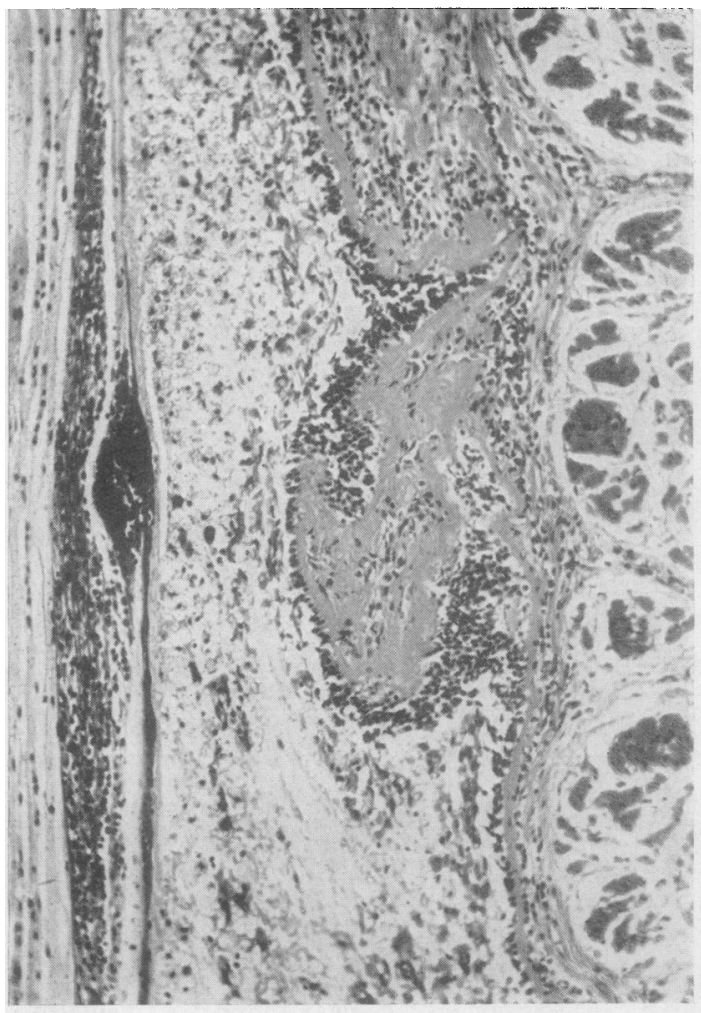

FIG. 3

in our series and recorded deaths from asthma in 을 childhood are rare. Eight of the nine patients were women, but this preponderance of females probably arose by chance as it does not occur in larger series of cases (Rackemann, 1944; Thicme and Sheldon, of 1938; Winer, Beakey, and Segal, 1950; Walton, N Penner, and Wilt, 1951). Only three of our patients gave a family history of asthma, but it is of interest 0 that the mother and aunt of one of them had both died in status asthmaticus. A.part from a history $\frac{2}{0}$ of hay fever in one case and of attacks being $\stackrel{\mathcal{D}}{\rightarrow}$ precipitated by pollen and dust in three others, 0 there was no evidence that allergy played an ${ }_{0}$ important part in the aetiology, though five of $\stackrel{\mathbb{D}}{\circ}$ the patients did show an absolute eosinophilia in 
FIG 4-Photomicrograph of bronchiole showing dilatation of wall and filling of lumen with mucus containing epithelial spirals. Haematoxylin and eosin, $\times 38$.

Fig. 5.-Photomicrograph of thickened basement membrane stained black. Reticulin stain, $\times 128$.

FIG. 6.-Photomicrograph showing area of squamous metaplasia in bronchial epithelium. Haematoxylin and eosin, $\times 132$.

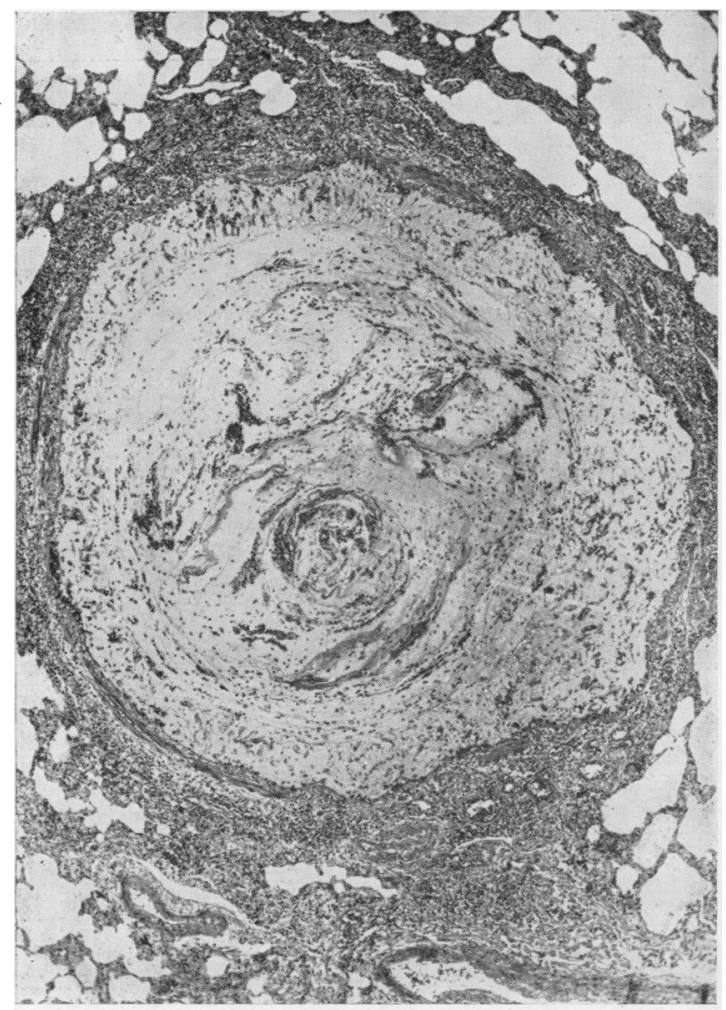

FIG. 4

the peripheral blood. Psychological factors appear to have been at least as important in these patients as in asthmatics generally. Seven of our nine patients had had asthma for eight years or less at the time of their death, and though reported cases show a very variable total duration of the disease a rather short history is in fact quite common. Williams (1952) found that 51 of 110 fatal cases $(46 \%)$ had had asthma for less than five years, and $44(40 \%)$ died within two years of the onset. The conclusion to be drawn is not that when asthma is of recent onset a fatal attack is particularly likely, but that it is possible. Seven of our patients had had very severe asthma, more or less continuous and only partially relieved by

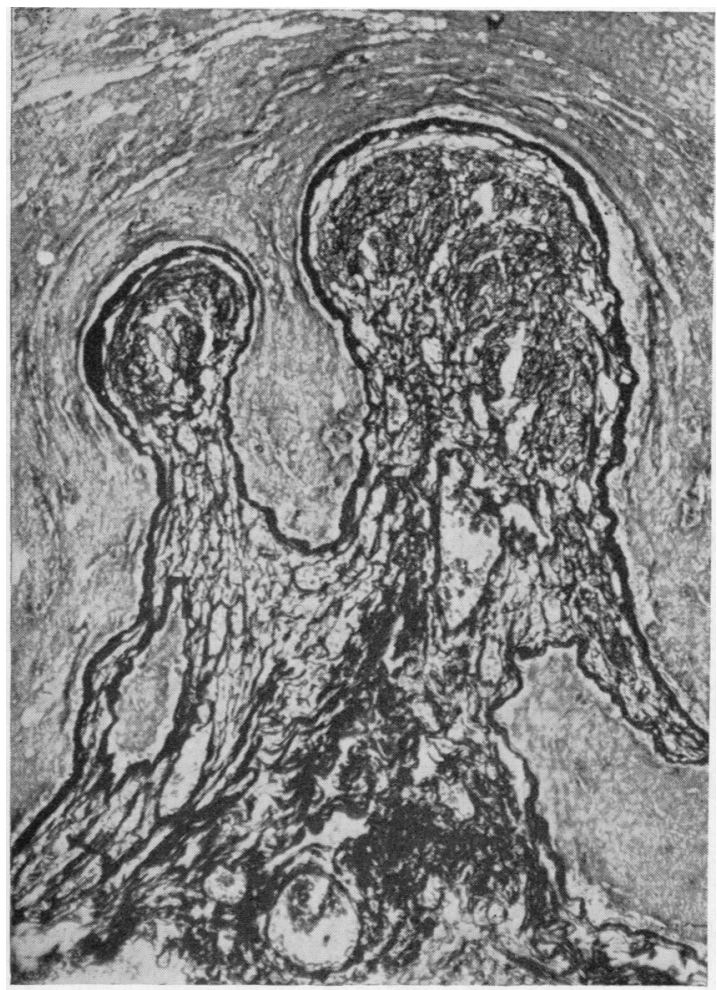

FIG. 5

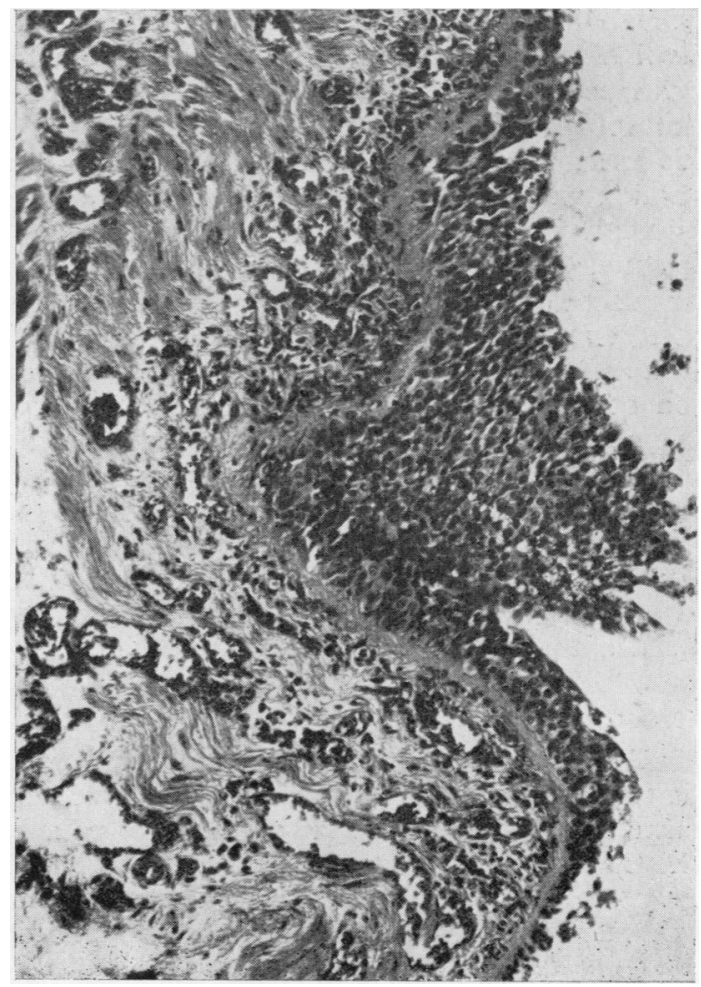

FIG. 6 
TABLE

SUMMARY OF CLINICAL ASPECTS OF NINE FATAL CASES OF ASTHMA

\begin{tabular}{|c|c|c|c|c|c|c|c|c|c|c|}
\hline & & $\begin{array}{c}\text { Age } \\
\text { (years) }\end{array}$ & Sex & $\begin{array}{l}\text { Age of } \\
\text { Onset } \\
\text { (years) }\end{array}$ & $\begin{array}{l}\text { Family } \\
\text { History }\end{array}$ & Allergy & $\begin{array}{l}\text { Psycho- } \\
\text { logical } \\
\text { Factor }\end{array}$ & Cyanosis & $\begin{array}{l}\text { Eosino- } \\
\text { philia }\end{array}$ & Respiratory Depressants \\
\hline Case 1 & . & 48 & $\mathbf{F}$ & 46 & + & - & + & $\begin{array}{l}\text { Not } \\
\text { recorded }\end{array}$ & $\begin{array}{l}1,450 \mathrm{per} \\
\text { c. } \mathrm{mm} \text {. }\end{array}$ & $\begin{array}{l}\text { Paraldehyde the day before } \\
\text { death }\end{array}$ \\
\hline, 2 & $\cdots$ & 33 & F & $\begin{array}{c}16 \\
\text { (severe } \\
\text { from } 32 \text { ) }\end{array}$ & $\begin{array}{l}\text { Not } \\
\text { recorded }\end{array}$ & - & - & + & - & $\begin{array}{l}\text { Paraldehyde }(28 \mathrm{ml} . \text { i.m. }) \text { in last } \\
24 \text { hours }\end{array}$ \\
\hline, 3 & $\cdots$ & 47 & $\mathbf{M}$ & 40 & + & - & - & Slight & - & 一 \\
\hline,, 4 & $\cdots$ & 53 & $\mathbf{F}$ & 49 & $\begin{array}{l}\text { Not } \\
\text { recorded }\end{array}$ & + & + & + & $\begin{array}{l}990 \text { per } \\
\text { c.mm. }\end{array}$ & $\begin{array}{l}\text { Paraldehyde }(5 \mathrm{ml} \text {. i.m.) } 5 \text { hrs. } \\
\text { before death }\end{array}$ \\
\hline ,. 5 & $\cdots$ & 53 & $\mathbf{F}$ & 52 & - & - & + & $\begin{array}{l}\text { Not } \\
\text { recorded }\end{array}$ & $\begin{array}{l}651 \text { per } \\
\text { c.mm. }\end{array}$ & $\begin{array}{l}\text { Paraldehyde }(7 \mathrm{ml} .) \text { by mouth } \\
\text { just before death }\end{array}$ \\
\hline, 6 & $\cdots$ & 64 & $\mathbf{F}$ & 42 & - & + & + & , & $\begin{array}{l}896 \text { per } \\
\text { c.mm. }\end{array}$ & $\begin{array}{l}\text { Sodium amytal, } 3 \text { grains }(0.2 \mathrm{~g} .) \text {, } \\
1 \mathrm{hr} \text {. before death }\end{array}$ \\
\hline, 7 & $\cdots$ & 26 & $\mathbf{F}$ & 22 & + & - & + & + & - & $\begin{array}{l}\text { Morphine, } \frac{1}{\text { grain }(15 \mathrm{mg}), 24} \\
\text { hrs. and paraldehyde (5 ml. } \\
\text { i.m.) } 2 \text { hrs. before death }\end{array}$ \\
\hline,, 8 & $\cdots$ & 46 & $\mathbf{F}$ & 43 & - & + & - & $\begin{array}{l}\text { Not } \\
\text { recorded }\end{array}$ & $\begin{array}{l}\text { Not } \\
\text { recorded }\end{array}$ & $\begin{array}{l}\text { Morphine, } \frac{1}{6} \text { grain }(10 \mathrm{mg} .), 35 \\
\text { hrs. before death }\end{array}$ \\
\hline,, 9 & $\ldots$ & 47 & $\mathbf{F}$ & 39 & - & + & + & + & $\begin{array}{l}2,375 \text { per } \\
\text { c. mm. }\end{array}$ & - \\
\hline
\end{tabular}

treatment, for some months before their final admission to hospital. This history is the usual one found in the recorded fatal cases, though occasionally death after only a brief attack of asthma has been reported (Walton and others, 1951). In our series the shortest duration of the final acute exacerbation which failed to show any response to anti-spasmodics was 18 hours; more often it lasted several days. At the end of this period death occurred suddenly without warning except in two patients who had a preterminal phase of collapse with falling blood pressure. Only two of our patients had been given morphine during the final illness, which is of interest in view of the common belief that death from asthma almost always follows the administration of an opium alkaloid. There can, however, be no doubt about the great danger of giving a respiratory depressant such as morphine to these patients. Paraldehyde was given to five of our patients shortly before they died, but it seems doubtful whether a hypnotic with so little effect on the respiratory centre can have played any significant part in the fatal outcome.

\section{CONCLUSIONS}

It has long been recognized that plugging of the smaller subdivisions of the bronchial tree with mucus is a constant finding in the lungs of patients who have died in status asthmaticus, and it is generally agreed that the consequent interference with pulmonary ventilation is a major factor in the cause of death. It does not seem to have been generally appreciated in the past that widespread detachment of ciliated epithelium is an equally constant and characteristic finding in histological preparations from the lungs of these patients. As ciliary activity is by far the most important mechanism by which mucus is normally removed from the smaller bronchi, loss of the ciliated epithelium seems the most probable explanation for the accumulation of mucus and bronchial obstruction. Presumably in a short attack of asthma the amount of ciliated epithelium lost is insufficient to prevent the expulsion of mucus and after the attack the bronchial epithelium regenerates. It may be postulated, however, that the longer the attack the greater will be the loss of ciliated epithelium and a stage may be reached at which mucus can no longer be removed from the smaller bronchi; clinically this stage is characterized by failure of the asthma to respond to anti-spasmodics. We believe that this is the mechanism in status asthmaticus which proves fatal. There is no doubt that the majority of patients diagnosed clinically as being in status asthmaticus recover, and presumably in these patients there is only partial bronchial plugging with added bronchial spasm which in time becomes amenable to treatment.

\section{SUMMARY}

The clinical and pathological features of nine patients dying in status asthmaticus, without evidence of infection or heart failure, are described. 
From a study of our patients and reported cases it appears that death in status asthmaticus occurs particularly in adult life and may occur in patients whose asthma is of quite recent onset.

The gross morbid appearances of the lungs of our patients conform to previous descriptions, namely dry, emphysematous lungs with widespread bronchial obstruction by mucus.

Microscopically, extensive detachment of the ciliated epithelium was found in all cases examined. The importance of this finding in the development and course of status asthmaticus is discussed.

\section{REFERENCES}

Bullen, S. S. (1952). J. Allergy, 23, 193

Curschmann, H. (1883). Dtsch. Arch. klin. Med., 32, 1.

Hilding, A. C. (1943). Ann. Otol. St. Louis, 52, 5.

Huber, H. L., and Koessler, K. K. (1922). Arch. intern. Med., 30, 689.

Moore, W. F. (1925). Amer. J. med. Sci., 169, 799.

Rackemann, F. M. (1944). J. Allergy, 15, 249.

Thieme, E. T., and Sheldon, J. M. (1938). Ibid., 9, 246.

Thomson, J. G. (1945). J. Path. Bact., 57, 213.

Unger, L. (1945). Sth. med. J., Bgham, Ala., 38, 513.

Walton, C. H. A., Penner, D. W., and Wilt, J. C. (1951). Canad. med. Ass. J., 64, 95.

Williams, D. A. (1952). Proceedings of the First Internationa Congress for Allergy, Zurich, 1951. Basel and New York.

Winer, B. M., Beakey, J. F., and Segal, M. S. (1950). Ann. intern Med., 33, 134. 